\title{
Gray Matter Oligodendrocyte Progenitors and Neurons Die Caspase-3 Mediated Deaths Subsequent to Mild Perinatal Hypoxic/Ischemic Insults
}

\author{
Raymond P. Rothstein Steven W. Levison \\ Department of Neurology and Neuroscience, Laboratory for Regenerative Neurobiology, \\ UMDNJ-New Jersey Medical School, Newark, N.J., USA
}

\section{Key Words}

Apoptosis $\cdot$ Cell death $\cdot$ Stroke $\cdot$ Subventricular zone $\cdot$

Choroid plexus

\begin{abstract}
With significant improvements in neonatal care, fewer infants sustain severe injury as a consequence of hypoxia/ischemia (H/l). However, the majority of experimental studies have inflicted moderate to severe injuries, or they have assessed damage to the caudal forebrain; therefore, to better understand how a mild $\mathrm{H} / \mathrm{l}$ episode affects the structures and cells of the rostral forebrain, we assessed the relative vulnerabilities of cells in the neocortex, striatum, corpus callosum, choroid plexus and subventricular zone (SVZ). To inflict mild H/l injury, the right common carotid artery was ligated followed by $1 \mathrm{~h}$ of hypoxia $\left(8 \% \mathrm{O}_{2}\right)$ at $37^{\circ} \mathrm{C}$. Regional vulnerabilities were assessed using TUNEL, active caspase- 3 and hematoxylin and eosin staining at 24 and $48 \mathrm{~h}$ of recovery. Scattered columns of cell death were observed in the neocortex with deep-layer neurons more vulnerable than more superficial neurons. The majority of these dying neurons appeared to be dying apoptotic rather than necrotic deaths. In addition, approximately $1 / 3$ of the apoptotic cells in the neocortex were $\mathrm{O} 4+$ oligodendrocyte progenitors. We also observed a decrease in NG2 staining within the affected regions of the forebrain. By
\end{abstract}

contrast, active caspase-3+/S-100 $\beta+$ astrocytes were not observed. Neurons and $\mathrm{O} 4+$ oligodendrocyte progenitors also died apoptotic deaths within the striatum. The lining cells of the choroid plexus also sustained damage. Elevated numbers of apoptotic cells were observed in the most lateral region of the SVZ and some of these dying cells were $\mathrm{O} 4+$. The most novel finding of this study, that oligodendrocyte progenitors in the gray matter are damaged and eliminated as a consequence of perinatal $\mathrm{H} / \mathrm{l}$, provides new insights into the histopathology and neurological deficits observed in infants who sustain mild $\mathrm{H} / \mathrm{l}$ brain injuries.

Copyright $(2005$ S. Karger AG, Basel

\section{Introduction}

Obstetrical and neonatal intensive care have improved dramatically over the past decades, resulting in a decreased incidence of the classic forms of perinatal brain damage including periventricular leukomalacia, periventricular hemorrhagic infarction and major intraventricular hemorrhage [Cooke, 1999]. However, magnetic resonance imaging reveals abnormalities in the subcortical white matter referred to as diffuse excessive high signal intensity on $\mathrm{T}_{2}$-weighted imaging in $75 \%$ of preterm infants at term-equivalent age [Maalouf et al., 1999; Counsell et al., 2003]. In addition, reduced gray matter vol-

\section{KARGER}

(ㄱ) 2005 S. Karger AG, Basel

Fax +41613061234

E-Mail karger@karger.ch

www.karger.com
Accessible online at: www.karger.com/dne
Steven W. Levison, $\mathrm{PhD}$

Department of Neurology and Neuroscience, Laboratory for Regenerative Neurobiology East Orange VA Medical Center, 385 Tremont Ave., Building 7 (127C) East Orange, NJ 07018 (USA)

Tel. +1 973676 1000, ext. 1155, Fax +1973 395 7233, E-Mail steve.levison@umdnj.edu 
umes have been noted in premature infants when studied at term-equivalent and at 8 years of age [Inder et al., 1999; Peterson et al., 2000]. These abnormalities are significant since the cohort of premature infants that survive continues to increase and infants who sustain perinatal insults are at risk for cerebral palsy, epilepsy or cognitive impairment [du Plessis and Volpe, 2002].

Vannucci et al. [1997] reported mild brain atrophy in postnatal day 7 (P7) rat pups subsequent to a unilateral common carotid ligation followed by $1 \mathrm{~h}$ of systemic hypoxia. In that study, the ipsilateral hemisphere (ILH) was on average $85 \%$ the size of the contralateral hemisphere (CLH). This mild atrophy is likely due to selective cell death with both pallial and subpallial structures after $1 \mathrm{~h}$ of hypoxia/ischemia (H/I) [Towfighi et al., 1997]. More recently, Geddes et al. [2001] have assessed the impact of a 75-min insult on cerebral damage and showed that mild damage leads to progressive cerebral degeneration. However, it has not yet been established whether only neurons or both neurons and glia die as a consequence of a mild insult, and if glial cells die, which ones are most vulnerable. In the study by Towfighi et al. [1997], a detailed analysis of the posterior forebrain was performed, whereas forebrain structures were not analyzed as extensively. Therefore, to better understand how a mild cerebral insult affects the developing rostral forebrain, in the present study we examined cell damage at 24 and $48 \mathrm{~h}$ of recovery following a 60-min H/I insult. We examined the neocortex, striatum, corpus callosum, subventricular zone (SVZ) and choroid plexus to determine the relative vulnerabilities of these brain regions, the locations of degenerating cells and the types of cells that were most vulnerable.

\section{Materials and Methods}

\section{Reagents}

Unless specified, standard laboratory reagents were obtained from VWR (Bridgeport, N.J., USA) and Fisher Scientific (Pittsburgh, Pa., USA). Paraformaldehyde and glutaraldehyde were purchased from Electron Microscopy Sciences (Fort Washington, Pa., USA). Normal goat serum was purchased from Gibco (Grand Island, N.Y., USA). Rabbit primary antibodies raised against active caspase-3 were purchased from Cell Signaling Technology (New England BioLabs, Beverly, Mass., USA). S-100 $\beta$ mouse monoclonal was purchased from Sigma. Rabbit anti-NeuN was purchased from Chemicon. The APC (Ab-7) monoclonal antibody clone CC1 was purchased from Oncogene Research Products. The NG2 mouse monoclonal antibody was provided by Bill Stallcup (Scripts Institute, La Jolla, Calif., USA).

\section{Perinatal Hypoxia Ischemia Model}

Timed pregnant Wistar rats were purchased from Charles River Laboratories (Charles River, Wilmington, Del., USA), housed in individual cages and fed high-fat lab chow. After normal delivery, the litter size was adjusted to 10 pups per litter. Two different groups of animals were used: controls and experimental hypoxic/ ischemic animals. Cerebral $\mathrm{H} / \mathrm{I}$ was produced in male and female 6-day-old rats (day of birth being $\mathrm{P} 0$ ) by a permanent unilateral common carotid ligation followed by a 1-hour exposure to systemic $8 \% \mathrm{O}_{2}$ balance $\mathrm{N}_{2}$ gas (nonhumidified) at $37^{\circ} \mathrm{C}$ as described previously [Rice et al., 1981; Vannucci et al., 1996; Levison et al., 2001]. After hypoxia, the pups were returned to their dam for recovery periods of 24 and $48 \mathrm{~h}$, at which time they were anesthetized and sacrificed by intracardiac perfusion. Controls received neither right carotid ligation nor hypoxia.

\section{Intracardiac Perfusions, Tissue Fixation and Sectioning}

Animals were perfusion fixed with 3\% paraformaldehyde in $0.1 M$ phosphate buffer. Brains were removed and immersion fixed in the same fixative overnight at $4^{\circ} \mathrm{C}$. For frozen sections, the brains were coronally blocked and placed in $30 \%$ sucrose (with $0.05 \%$ sodium azide) overnight. The following day, the tissue was mounted in cassettes with OCT and frozen over a bath of ethanol and dry ice. Coronal sections were cut at $12 \mu \mathrm{m}$ at the level of the anterior commissure, -0.3 to -0.6 from the bregma and held at $-80^{\circ} \mathrm{C}$ until used. All sections were thaw mounted onto Superfrost plus slides. For O4 staining, brains were perfusion fixed with 3\% paraformaldehyde and $0.1 \%$ glutaraldehyde. Sections were cut at $30 \mu \mathrm{m}$ on a vibratome.

\section{Immunofluorescence and TUNEL}

Immunofluorescence was performed with standard methods using antibodies to $\mathrm{NG} 2, \mathrm{O} 4$ and $\mathrm{CC} 1$ which recognize the early, late and mature oligodendrocytes, respectively, and using S-100 which recognizes astrocytes, and $\mathrm{NeuN}$ which recognizes mature neurons. After blocking for $1 \mathrm{~h}$, sections were incubated in rabbit antiactive caspase-3; CC1, S-100ß; O4, NG2 or NeuN overnight at $4^{\circ} \mathrm{C}$. After extensive washes, the sections were incubated in appropriate secondary antibodies with or without tyramide signal amplification. All slides were counterstained with DAPI and coverslipped with GEL/MOUNT (Biomeda, Foster City, Calif., USA). TUNEL staining was performed as described previously [Romanko et al., 2004]. Images for TUNEL and immunohistochemistry were captured using a Photometrics cooled charged-coupled device camera (Tucson, Ariz., USA) interfaced with IP Lab scientific imaging software (Scanalytics Fairfax, Va., USA) mounted on an Olympus BX-50 upright microscope.

\section{Histological Analysis}

Defined areas of both the neocortex and striatum were evaluated to determine whether an individual pup had sustained any damage. The most vulnerable areas of the neocortex (fig. 1A) and striatum (fig. 1B) were examined. As the immature striatum is extremely sensitive to this insult, a damage score was assigned by assessing two random $60 \times$ fields of the striatum, located approximately $0.5 \mathrm{~mm}$ dorsal and $0.5 \mathrm{~mm}$ lateral to the SVZ. Damage was characterized as mild when there were fewer than $50 \%$ necrotic and apoptotic cell profiles in the region of the striatum assessed. Brains were characterized as moderately damaged when $50-75 \%$ of neurons in this region of the striatum were dead. 
Fig. 1. Drawing of $\mathrm{P} 6$ rat brain labeling regions examined in this study of a mild $\mathrm{H} / \mathrm{I}$ insult. This drawing shows the area of the neocortex (A), striatum (B), and choroid plexus $(\mathrm{C})$ where the hematoxylin-and-eosin-stained and TUNEL images were captured. The medial (D), mediolateral(E), and lateral $(\mathrm{F})$ regions of the $\mathrm{SVZ}$ are illustrated in the blowup.

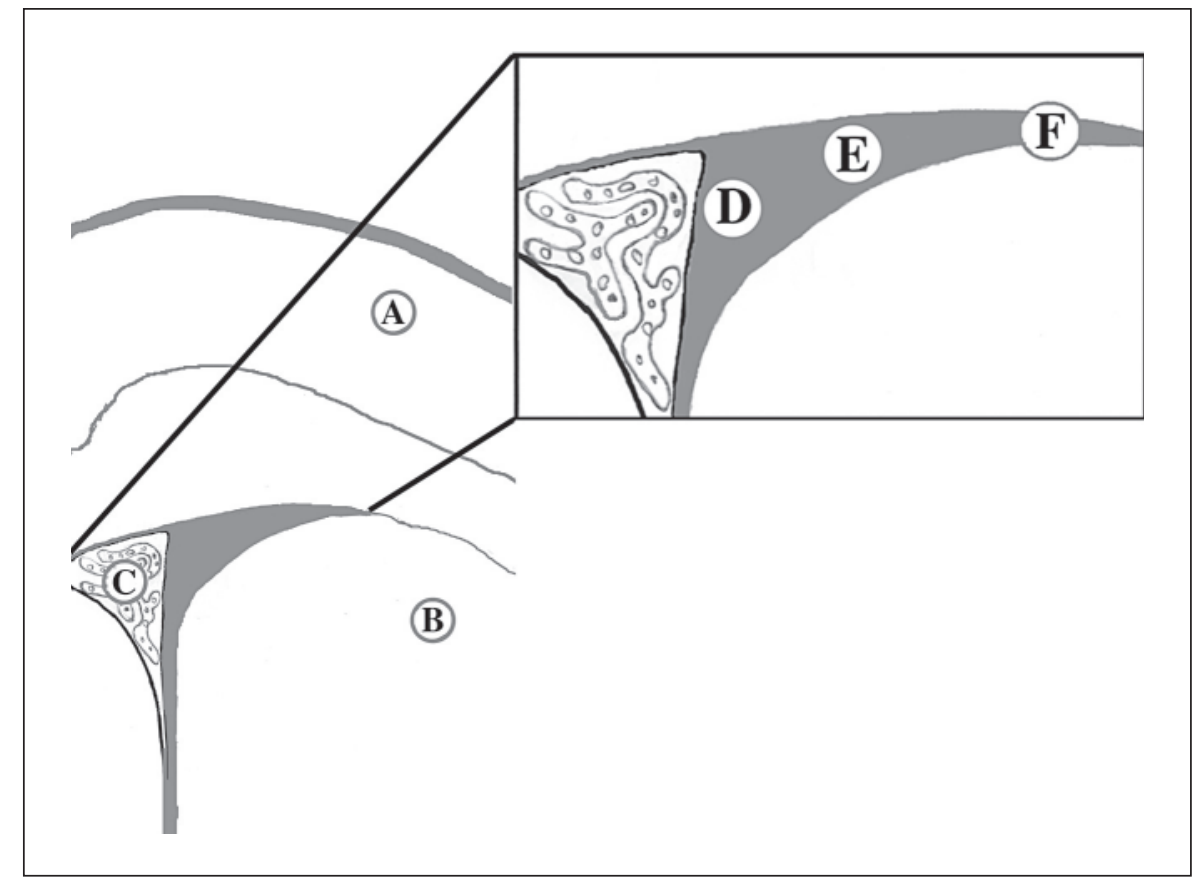

\section{Results}

In the present study, we examined cell damage at $24 \mathrm{~h}$ $(\mathrm{n}=10)$ and $48 \mathrm{~h}(\mathrm{n}=17)$ of recovery following a $60-\mathrm{min}$ $\mathrm{H} / \mathrm{I}$ insult to determine the relative vulnerability of cells in the neocortex, striatum, corpus callosum, SVZ and choroid plexus to a mild insult. With the time-limited exposure to H/I employed, we confirmed that the extent of damage sustained by individual animals was variable. In addition to the 27 brains included for study, there were 5 brains analyzed with no visible damage and 4 brains that had sustained greater than $50 \%$ neuronal damage within the striatum at $24 \mathrm{~h}$ of recovery. At $48 \mathrm{~h}$ of recovery, 2 brains showed no damage and 4 brains had sustained greater than 50\% neuronal damage within the striatum. As these animals failed to meet the criteria for inclusion in the study, these brains were excluded from analysis.

Neocortical damage was evident at approximately $1 \mathrm{~mm}$ lateral from the lateral ventricle in the region depicted in figure 1A. Approximately $30 \%$ of the cells within this region of the neocortex on the ILH had pyknotic nuclei. As reported previously, the damage sustained is principally columnar, thus regions with columns of dying cells were seen, but in none of the animals examined were more than $50 \%$ of the nuclei within the neocortex pyknotic or necrotic. The extent of damage in the neocortex
Table 1. Distribution of pyknotic nuclei at 24 and $48 \mathrm{~h}$ of recovery in the neocortex and striatum

\begin{tabular}{lccll}
\hline \multicolumn{5}{c}{ Pyknotic nuclei } \\
\cline { 2 - 5 } & $1-20 \%$ & $20-30 \%$ & $30-40 \%$ & $40-50 \%$ \\
\hline 24 hof recovery $(n=10)$ & & & \\
Striatum & 1 & 1 & 5 & 3 \\
Neocortex & 1 & 3 & 3 & 3 \\
\hline 48 hof recovery $(n=17)$ & & & \\
Striatum & 1 & 4 & 7 & 5 \\
Neocortex & 4 & 6 & 6 & 1 \\
\hline
\end{tabular}

The extent of damage was assessed from two random $60 \times$ fields of the striatum and neocortex of each animal (as identified in figure 1 ) at 24 and $48 \mathrm{~h}$ of recovery. The values represent the numbers of animals with the indicated percentage of pyknotic nuclei within these specific regions at each time point.

(and striatum) was rated and grouped and the distribution of damage amongst animal subjects is provided in table 1 . In the ILH, the inner layers of the neocortex sustained more damage than the outer layers at $24 \mathrm{~h}$ of recovery as reported by Towfighi et al. [1997]. Many of the dying cells had pyknotic nuclei characteristic of apoptotic cells. Often cells with apoptotic bodies within their 
Fig. 2. The neocortex and striatum at $24 \mathrm{~h}$ of recovery following a mild $\mathrm{H} / \mathrm{I}$ insult. A Appearance of the CLH neocortex stained with hematoxylin and eosin. B ILH. Arrowheads demark a small column of pyknotic nuclei. C Appearance of the CLH neocortex stained with TUNEL. D The ILH neocortex stained using TUNEL. Arrowheads mark TUNEL+ cells. E Appearance of the CLH striatum stained with hematoxylin and eosin. F The ILH striatum stained with hematoxylin and eosin. Arrowheads demark pyknotic nuclei. Appearance of the CLH striatum stained with TUNEL (G) vs. the ILH striatum (H) which shows TUNEL+ cells (arrowheads). I Appearance of dying cells in the severely damaged neocortex. Cells have classic features of necrotic cells with clumped and marginalized chromatin. $\mathbf{J}$ Appearance of dying cells in a mildly damaged brain. Cells have the classic features of apoptotic cells with condensed shrunken nuclei. A, B, E, F, I, $\mathbf{J}$ Stained with hematoxylin and eosin. C, D, G, H stained using TUNEL with a light hematoxylin counterstain. Scale bars: $25 \mu \mathrm{m}(\mathbf{A}, \mathbf{B}, \mathbf{E}, \mathbf{F}) ; 30 \mu \mathrm{m}$ (C, D, $\mathbf{G}, \mathbf{H}) ; 5 \mu \mathrm{m}(\mathbf{I}, \mathbf{J})$.
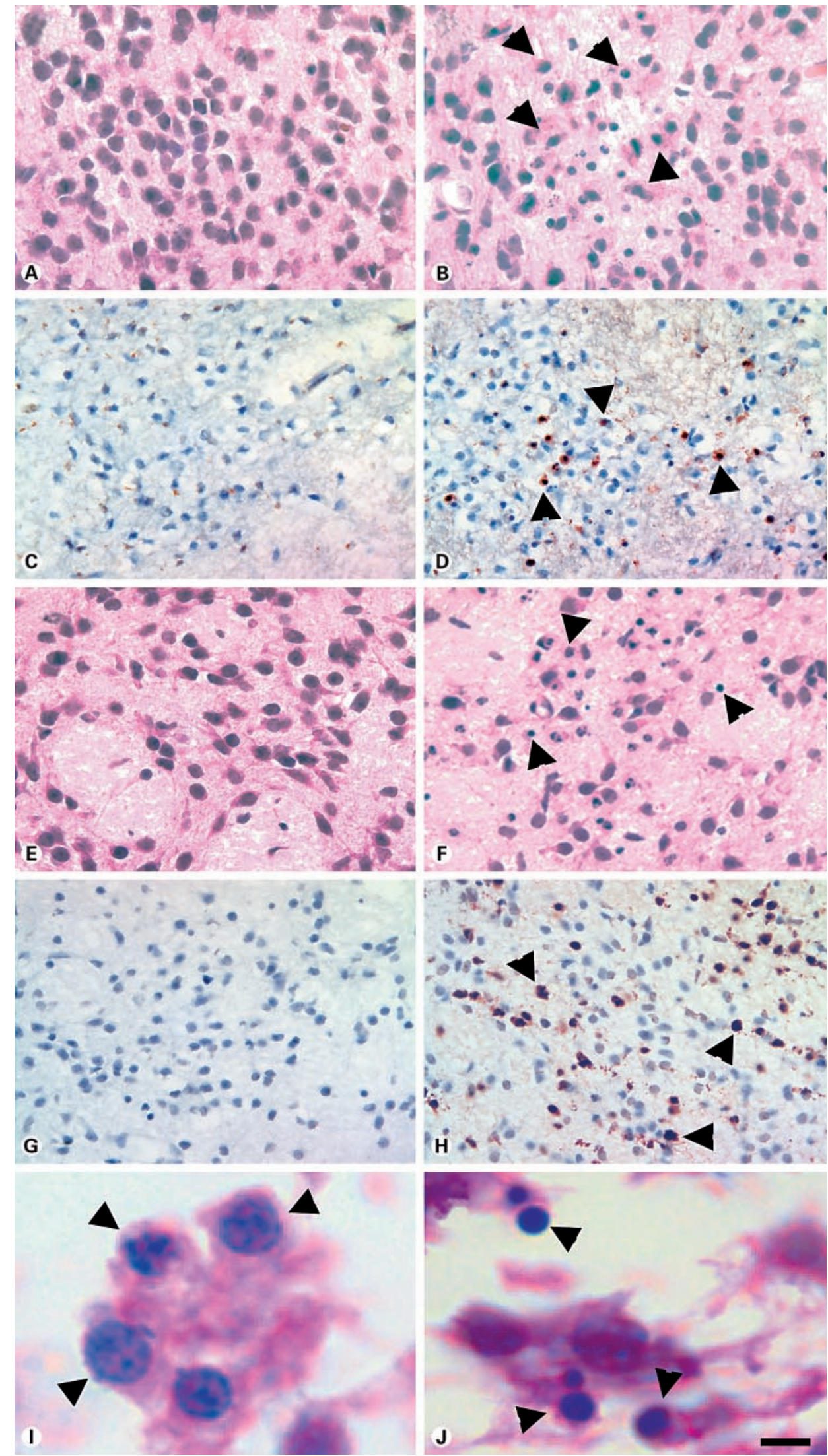
cytoplasm could be identified (fig. 2B, J); however, some cells with the features of hybrid cell deaths were also observed (fig. 2B). Staining for active caspase-3 and NeuN confirmed that a subset of the dying cells in these regions were neurons (fig. $3 \mathrm{H}$ ). Profile counts revealed that 60 $70 \%$ of the dying cells were NeuN+/active caspase- $3+$. In animals with a greater degree of damage, cell death extended into the outer layers of the neocortex. In addition, with more severe damage cells with classical features of necrotic cell death could be observed (fig. 2I). Pyknotic nuclei (fig. 2A) or TUNEL+ cells (fig. 2C) were rarely found in the neocortex of the CLH.

As immature oligodendrocytes have been shown to be especially sensitive to damage in the perinatal brain, we stained for $\mathrm{NG} 2, \mathrm{O} 4$ and $\mathrm{CC} 1$, which are markers of the different stages of the oligodendrocyte lineage, to assess which stage was most vulnerable to a mild H/I insult. When the neocortex was stained using antibodies to NG2, there was significantly less NG2 staining in the ILH at $24 \mathrm{~h}$ as compared to the CLH (fig. 3A, B). As the decreased NG2 staining could be due to either proteolytic degradation of the NG2 or to a decrease in the number of NG2+ cells, we stained the neocortex for active caspase- 3 and NG2. While many cells in the neocortex stained for active caspase-3, few NG2+ cells also stained for active caspase-3 (fig. 3B, inset). Thus, some NG2 cells die as a consequence of this insult; however, the loss of NG2 is likely due to proteolytic degradation of NG2 subsequent to an $\mathrm{H} / \mathrm{I}$ insult.

To determine whether satellite oligodendrocytes, which are the nonmyelinating oligodendrocytes of the neocortex, were dying, we stained sections using the $\mathrm{CC} 1$ monoclonal antibody, which stains immature and mature oligodendrocytes, and we stained for active caspase-3. $\mathrm{CC} 1$ and active caspase-3 double-positive cells were rare (fig. 3G). Whereas few NG2 and $\mathrm{CC} 1$ cells stained for active caspase- 3 in the neocortex, staining for $\mathrm{O} 4$ and active caspase-3 revealed many double-positive cells (fig. 3D). Profile counts revealed that these $\mathrm{O} 4+$ cells represented approximately $30 \%$ of the active caspase- $3+$ cells in the neocortex. The majority of the brains examined also showed an increase in TUNEL+ cells in the white matter of the corpus callosum as well as a thinning of cellular processes, as has been described.

Both satellite oligodendrocytes and a subset of astrocytes label for $\mathrm{CC} 1$; therefore, we labeled cells in the neocortex for S-100 $\beta$ and active caspase- 3 to determine whether any astrocytes were dying. Only four S-100ß/active caspase-3+ cells were observed when sections were viewed at low power ( $\mathrm{n}=6$ animals; fig. $3 \mathrm{C}$ ). Although these few cells were double-labeled when viewed at low power, in each case, when these apparently doubled cells were reexamined at higher power, small cells that were labeled for active caspase- 3 could be identified inside the cytoplasm of the $\mathrm{S}-100 \beta+$ cells as seen in figure $3 \mathrm{C}$ (inset). Thus, the $\mathrm{S}-100 \beta+$ astrocytes were phagocytosing adjacent dying cells but were not, themselves, dying by apoptosis.

The striatum was always more severely damaged than the neocortex, with the dorsolateral striatum more vulnerable than the ventral striatum (fig. 2F). On average, approximately $30-40 \%$ of the cells in the overall striatum contained pyknotic nuclei at $24 \mathrm{~h}$ of recovery and no more than $50 \%$ of those cells within the most vulnerable region had pyknotic nuclei (table 1). Most of the cells with pyknotic nuclei also were TUNEL+ (fig. 2H). Staining for O4 and active caspase- 3 revealed many double-positive late oligodendrocyte progenitors (fig. 3E). Interestingly, the preponderance of these double-positive cells was located in the most dorsolateral area of the striatum. As the overall damage to the striatum increased, dying cells became evident in more medial regions of the striatum. Few if

\section{(For figures see next pages.)}

Fig. 3. Neocortical oligodendrocyte damage following a mild $\mathrm{H} / \mathrm{I}$ insult. A Appearance of NG2 staining (green) of the CLH neocortex. Nuclei are stained with DAPI (blue). B In the ILH neocortex, fewer NG2+ cells are seen. The inset shows two, rare, NG2+ cells that are also stained for active caspase-3 (red). C ILH neocortex stained for S-100 3 (green) and active caspase-3 (red). One S-100 $\beta+$ cell appears to be double positive. Inset: another S-100 $\beta+$ cell that appeared to stain for active caspase- 3 is shown at high magnification. This $\mathrm{S}-100 \beta+$ cell is in fact phagocytosing an adjacent apoptotic cell. Arrow points to the distinct apoptotic bodies of the nucleus of this dying cell. D Many O4 (green)/active capase-3 (red) double-positive cells are observed in the neocortex and in the striatum (E). F An O4/active caspase-3 double-positive cell in the mediolateral SVZ. G CC1 (green) and active caspase-3 (red) staining in the deep laminae of the neocortex. $\mathbf{H ~ N e u N ~ ( g r e e n ) ~ a n d ~ a c t i v e ~}$ caspase-3 (red) staining in the deep laminae of the neocortex. Scale bars: $25 \mu \mathrm{m}$ (A, B), $12 \mu \mathrm{m}$ (inset); $15 \mu \mathrm{m}$ (C), $9 \mu \mathrm{m}$ (inset); $9 \mu \mathrm{m}$ (D, E, G, H); $4 \mu \mathrm{m}$ (F).

Fig. 4. The choroid plexus and SVZ at $24 \mathrm{~h}$ of recovery following a mild H/I insult. Appearance of the CLH ventricle and choroid plexus (A) vs. the ILH choroid plexus (B) which shows debris (arrowheads) in the lateral ventricle. Appearance of the CLH ventricle and choroid plexus (C) vs. the ILH choroid plexus (D) which shows TUNEL+ cells inside the lateral ventricle. A representative lowpower image of the CLH SVZ(E) vs. the ILH SVZ(F), which shows thinning. Appearance of the CLH SVZ (G) vs. the ILH SVZ (H), which contains TUNEL+ cells (arrowheads). Scale bars: $30 \mu \mathrm{m}(\mathbf{A}$, B); $40 \mu \mathrm{m}$ (C, D); $150 \mu \mathrm{m}$ (E, F); $25 \mu \mathrm{m}(\mathbf{G}, \mathbf{H})$. 


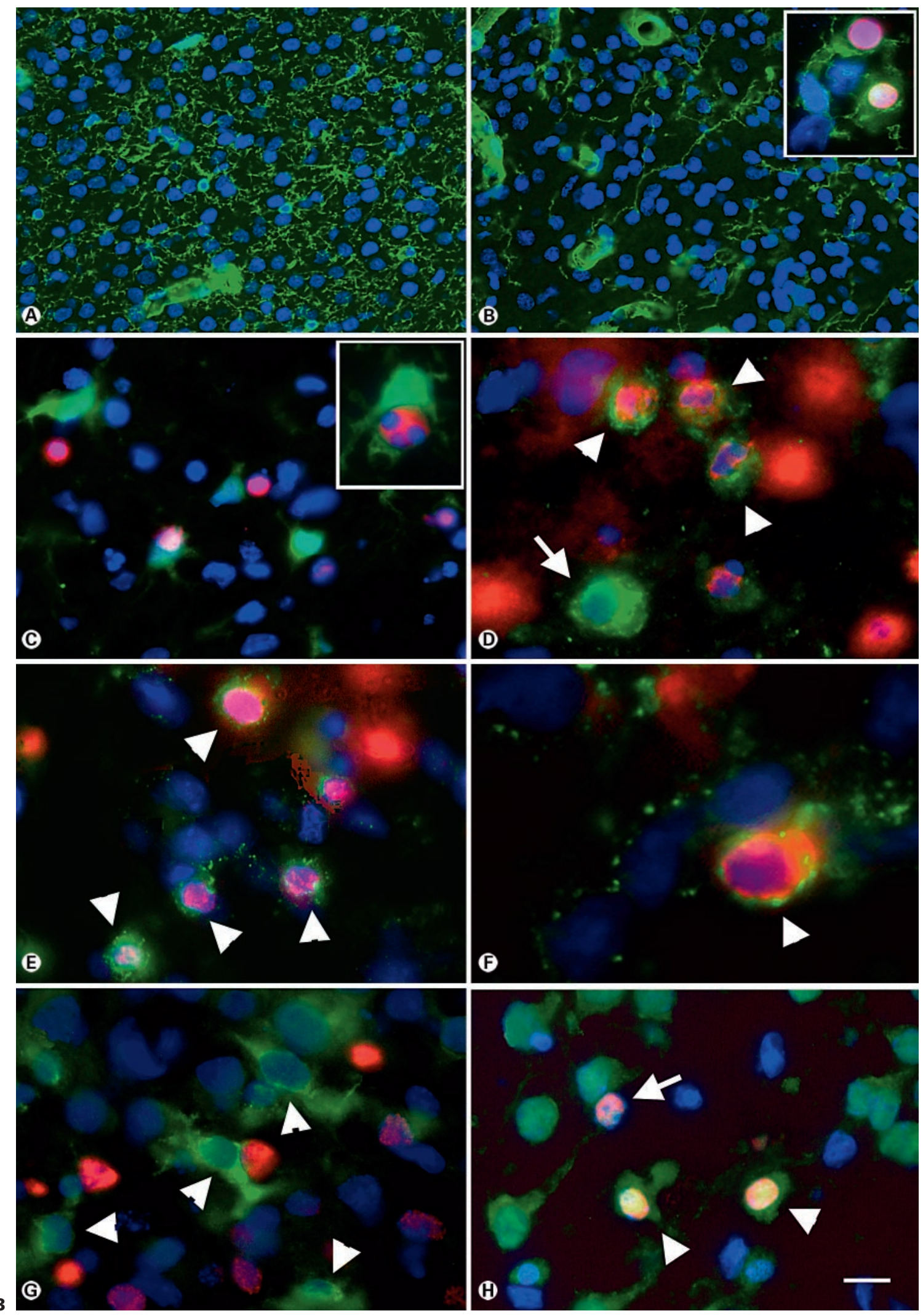




any pyknotic nuclei or TUNEL+ cells were observed in the CLH striatum (fig. 2E, G).

We have previously reported that the choroid plexus is vulnerable to moderate $\mathrm{H} / \mathrm{I}$ [Rothstein and Levison, 2002], and in this cohort of mildly damaged brains, we again found damage to the choroid plexus. In a hematoxylin and eosin stain, cellular debris could be identified within the lateral ventricles (fig. 3B). Furthermore, approximately $50 \%$ of cells in the choroid plexus stained for TUNEL at $24 \mathrm{~h}$ of recovery (fig. 3D). The dying cells appeared to be situated among the lining cells. Typically, the choroid sustained only partial damage. At $24 \mathrm{~h}$ of recovery, $80 \%$ of the choroid plexuses examined had mild to moderate damage, with approximately $25-50 \%$ of cells dying. The choroid plexuses were normal in $10 \%$ of the brains that exhibited signs of damage. Approximately $10 \%$ of the lateral ventricles had no choroid plexuses on the ILH $(n=10)$, but damaged choroid plexuses may have been extracted during tissue processing. No cellular debris or TUNEL+ cells were located within the lateral ventricle of the CLH (fig. 4A, C). At $48 \mathrm{~h}$ of recovery, approximately $40 \%$ of the ILHs examined had mild to moderate choroid plexus damage, $6 \%$ had severe damage, $6 \%$ were normal, and the remaining lateral ventricles had no choroid plexuses within them $(n=15)$.

As the focus of our research has been on the changes to the SVZ after $\mathrm{H} / \mathrm{I}$, we assessed changes to 3 subregions of the dorsolateral ILH SVZ, as depicted in figure 1: the lateral tail, the mediolateral SVZ and the medial SVZ at 24 and $48 \mathrm{~h}$ of recovery. By hematoxylin and eosin stain at $24 \mathrm{~h}$ of recovery (fig. 4F), the ILH SVZ was uniformly less cellular as compared to the CLH SVZ (fig. 4E). Approximately $80 \%$ of the brains had thinning of the SVZ in the ILH at $24 \mathrm{~h}$ of recovery. At $48 \mathrm{~h}$ of recovery, approximately $70 \%$ of the brains had thinning of the SVZ. This result is similar to that which we have observed with moderate perinatal brain damage [Romanko et al., 2004]. Although there was a trend towards a larger ipsilateral SVZ as appears in figure $4 \mathrm{~F}$, measurements of the area of the $S V Z$ revealed that this trend was not significant.

With but a few exceptions, the damage to the SVZ was proportional to the damage sustained by the striatum. Both necrotic and apoptotic cells were observed by hematoxylin and eosin $(n=6)$. Many TUNEL+ cells (arrowheads) were also observed in the ILH SVZ (fig. 4H), whereas few TUNEL+ cells were observed in the CLH SVZ (fig. 4G). Although the overall SVZ showed degeneration, the most noticeable change was in the lateral tail region. Here it was not uncommon to find multiple TUNEL+ cells within a single high-power microscope field. The mediolateral region of the ILH also contained more pyknotic nuclei (fig. 4H) than the CLH mediolateral SVZ. By contrast, the medial region of the SVZ of the ILH had very few pyknotic nuclei or necrotic cells, but some swelling was observed within this region, as compared to the medial region of the CLH. An increase in cellularity in the medial region of the ILH as compared to the medial region of the CLH was observed in approximately $8 \%$ of the brains $(\mathrm{n}=25)$. Staining for O4 and active caspase- 3 revealed dying late oligodendrocyte progenitors within the lateral tail of the SVZ (fig. 3F). None of the active caspase-3+ cells in the SVZ stained for $\mathrm{CC} 1$.

\section{Discussion}

Many studies have characterized the histopathology resulting from severe perinatal $\mathrm{H} / \mathrm{I}$ brain damage, whereas there are more limited reports of the histopathology resulting from mild $\mathrm{H} / \mathrm{I}$ damage. One of the purposes of this study was to contrast a mild insult with our previous results obtained using a moderate to severe insult. Specifically, we wanted to determine which regions of the rostral forebrain are most vulnerable, which areas within those regions are most vulnerable and we wanted to determine which cell types are most vulnerable. Particularly, we were very interested in knowing whether the cells of the SVZ were affected by a mild insult. Here we report that (1) the striatum and choroid plexus are the most vulnerable structures affected by a mild H/I insult; (2) deeplayer neurons in the neocortex are deleted to a greater extent than superficial neurons; (3) late oligodendrocyte progenitors in the neocortex and striatum die caspase-3mediated deaths subsequent to a mild insult; (4) NG2 expression is decreased acutely following a mild $\mathrm{H} / \mathrm{I}$ insult, and (5) oligodendrocyte progenitors are deleted from the lateral SVZ.

The Significance of Choroid Plexus Lining Cell Death

The choroid plexus plays a pivotal role in the production and composition of cerebrospinal fluid (CSF) and the tight junctions between the ependymal cells of the choroid plexus are the physical site of the blood-CSF barrier. The choroid plexus regulates ion homeostasis and restricts small injurious molecules to permeating into the brain. It also regulates the transport of small molecules into (e.g. glucose and amino acids) and out (e.g. glutamate and lipid-soluble toxins) of the brain. The demise of this blood-CSF barrier would allow proteins, cytokines, excit- 
atory amino acids, calcium and other substances to go pass in an unregulated fashion into the brain. As the ependymal cells lining the ventricles are permeable to relatively large proteins such as horseradish peroxidase [Brightman and Reese, 1969], substances that accumulate in the CSF could have a detrimental effect on the surrounding brain parenchyma. This abnormal CSF would increase hydraulic conductivity and lead to increased interstitial fluid (vasogenic edema). The rates and routes of clearance would depend on the patency of low resistance of the interstitial fluid pathways present in the tissue [Blaumanis et al., 1990; Ohata and Marmarou, 1992; Abbott, 2004], leading to different degrees of damage based on clearance mechanisms. Since energy failure causes the initial, or primary, cell death following an H/I insult, damage to the choroid plexus, and the subsequent demise of the blood-CSF barrier, may contribute to the progressive cell death that occurs after mild neonatal H/I, as described by Geddes et al. [2001]. Despite a number of research articles describing choroid plexus damage after $\mathrm{H} / \mathrm{I}$ in rodents, very few clinical studies have evaluated the acute effects of $\mathrm{H} / \mathrm{I}$ on the human choroid plexus [Bernert et al., 1988; Mito et al., 1989].

\section{Loss of SVZ Cells Will Reduce}

Oligodendrogliogenesis

We previously demonstrated that $\mathrm{H} / \mathrm{I}$ in the immature rat without hemorrhage or infection dramatically and chronically deletes cells from the SVZ [Levison et al., 2001]. However, in a more recent study, we reported that SVZ was relatively resistant to damage as compared to cells of the neocortex and striatum subsequent to a moderate H/I insult [Romanko et al., 2004]. Therefore, we hypothesized that the SVZ might pass unscathed by a mild $\mathrm{H} / \mathrm{I}$ insult. Contrary to this hypothesis, we observed thinning of the SVZ, as well as dying cells in the mediolateral and lateral regions. Although there was less cell death after a mild insult than observed following a moderate insult, the amount of cell death was significant when compared to the CLH. Thinning of the SVZ occurred in $70-80 \%$ of the brains analyzed. Many of the apoptotic cells within the SVZ stained with $\mathrm{O} 4$, a marker for late oligodendrocytes precursors. These cells are highly susceptible to hypoxic-ischemic brain damage in part due to their sensitivity to glutamate [Back et al., 2002; Ness and Wood, 2002]. In these studies, we did not assess whether PSA-NCAM+ cells within the SVZ were dying, although our previous studies would suggest that indeed these cells are also vulnerable. As these late oligodendrocyte progenitors are capable of producing over 50 daughters apiece [Levison et al., 1999], deleting these cells from the SVZ will contribute to the subsequent reduction of the number of white and gray matter oligodendrocytes.

We also observed decreased NG2 staining in the neocortex after H/I. As we observed few NG2+ cells, it is not likely that the loss of NG2 is due to death of this population but rather to the proteolytic degradation of NG2. Since the NG2 proteoglycan coimmunoprecipitates with the PDGF-alpha receptor, and since decreasing NG2 levels reduces the proliferative response of oligodendrocyte progenitors to PDGF, decreased levels of NG2 after H/I will likely further compromise the production of oligodendrocytes in the gray matter [Nishiyama et al., 1996].

\section{Neocortical Oligodendrocyte Depletion Will Likely}

Contribute to Deficits in Cognitive Function

Whereas depletion of white matter oligodendrocytes is frequently cited as the cellular basis for abnormal neurological function, a shortage of neocortical oligodendrocytes will alter brain function as well because the satellite oligodendrocytes of the gray matter perform numerous functions important for maintaining homeostasis. Gray matter oligodendrocytes buffer potassium, chloride and bicarbonate, they accumulate $\gamma$-amino butyric acid and they produce neurotrophins [Kettenmann et al., 1983; Reynolds and Herschkowitz, 1984; Sapirstein et al., 1984; Levi et al., 1986; Byravan et al., 1994; Dai et al., 2003]. The majority of oligodendrocytes in the gray matter are positioned immediately adjacent to neurons as so-called perineuronal satellite oligodendrocytes. Because satellite oligodendrocytes do not appear to produce myelin, their major function may be to support neurons by performing the abovementioned functions. The deletion of the gray matter oligodendrocytes that we have documented here may contribute to deficits in cognitive functions later in life.

\section{Mechanisms of Necrosis and Apoptosis}

Excessive extracellular levels of excitatory amino acids can kill neurons by activating (NMDA) receptors. In neurons, glutamate receptor activation leads to an increase in intracellular $\mathrm{Ca}^{2+}$ levels, resulting in destructive intracellular processes leading to necrotic, hybrid or apoptotic cell deaths. NMDA receptors directly activate neuronal nitric oxide synthase and the generation of nitric oxide can cause oxidative damage and cell death [Dugan and Choi, 1994]. Glutamate can also kill oligodendrocyte progenitors by activating AMPA/kainate receptors to stimulate hybrid and apoptotic deaths, although it is not clear whether the mechanisms leading to their demise are the same [McDonald et al., 1998; Ness and Wood, 2002]. 
The striatum is a major relay station for cortical information through the basal ganglia and our studies confirm that the cells of the striatum are deleted following a mild $\mathrm{H} / \mathrm{I}$ insult. Medium spiny neurons are the largest population of neurons within the striatum [Preston et al., 1980; Graybiel et al., 1994]. These neurons are small GABAergic projection neurons with glutamatergic and dopaminergic inputs. Medium spiny neurons contain NMDA receptors. Following an $\mathrm{H} / \mathrm{I}$ insult, high levels of extracellular glutamate activates these NMDA receptors which can be excitotoxic. The cholinergic interneurons, a smaller population of cells in the striatum, are selectively spared following ischemia and excitotoxic damage [Pulsinelli, 1985; Beal et al., 1986]. As we show here, with a moderate perinatal $\mathrm{H} / \mathrm{I}$ insult the majority of damaged striatal neurons die necrotic or hybrid cell deaths, whereas with a mild injury a greater proportion die classic apoptotic cell deaths [Martin et al., 1998; Rothstein and Levison, 2002].

Apoptosis is an energy-dependent highly regulated cell death. Apoptosis may be triggered by internal signals within the cell, receptor-mediated death effectors such as the Fas ligand or $\mathrm{TNF} \alpha$, or by reactive oxygen species such as nitric oxide or hydrogen peroxide. We observed that many more cells in the striatum and neocortex underwent apoptosis in the mild insult, whereas they died hybrid and necrotic deaths with the moderate insult. Following a mild insult where energy depletion is not complete, but the cell has sustained damage from oxidative stress, the cell may activate the apoptotic death machinery.

We suspect that Fas activation is an important mediator of the cell death that we have documented after mild injury since past studies have shown that $\mathrm{H} / \mathrm{I}$ induces and activates the Fas death receptor in the neonatal brain [Northington et al., 2001a, b]. Intracellular signaling by Fas receptor activation is complex. Fas receptor activation may lead to necrosis, apoptosis, cell survival or proliferation, depending on the stimulus [Kawahara et al., 1998; Nagata, 1999; Matsumura et al., 2000]. In a study of $\mathrm{H} / \mathrm{I}$ injury on wild-type and Fas-null P7 mice performed by Graham et al. [2004], an increase in proteins associated with extrinsic mediated pathway of apoptosis was observed. In wild-type mice, a significant increase in Fas death receptor was observed compared with the control at $24 \mathrm{~h}$ of recovery. Also, significant increases in cleaved caspase- 8 , cleaved caspase- 9 and cleaved caspase-3 were observed. Confirming the importance of Fas in cell death after perinatal H/I, histological analyses of C57Bl/6J wild types and Fas receptor nulls performed at
$72 \mathrm{~h}$ of recovery revealed significantly less injury in the neocortex, striatum and thalamus of mice lacking the functional Fas death receptor as compared to the wildtype mice [Graham et al., 2004].

There is good reason to hypothesize that elevated levels of glutamate also contribute to the oligodendroglial death we have observed. Studies comparing the vulnerability of different maturational stages of oligodendroglial cells to glutamate toxicity revealed that cells at the O4+/O1- stage are the most sensitive to kainate and to glutamate-mediated death [McDonald et al., 1998]. Furthermore, in vitro studies of late oligodendrocyte progenitors demonstrate that glutamate induces a dose-dependent increase in the apoptotic death of the late oligodendrocyte progenitor by stimulating Bax translocation to the mitochondria, release of cytochrome $\mathrm{c}$ and the subsequent activation of caspase-3. The translocation of Bax and the release of cytochrome $\mathrm{c}$ can be prevented by IGF1 [Ness and Wood, 2002; Ness et al., 2004]. As levels of IGF-1 mRNA are decreased as a consequence of H/I [Lee et al., 1996], decreased levels of IGF-1 combined with elevated levels of glutamate may create conditions that will result in the demise of these cells.

\section{Acknowledgements}

The authors would like to thank Mathew Covey for helpful suggestions on the manuscript. This work was supported by MH 59950 and HD 30705 awarded to S.W.L. 


\section{References}

Abbott NJ (2004): Evidence for bulk flow of brain interstitial fluid: Significance for physiology and pathology. Neurochem Int 45:545-552.

- Back SA, Han BH, Luo NL, Chricton CA, Xanthoudakis S, Tam J, Arvin KL, Holtzman DM (2002): Selective vulnerability of late oligodendrocyte progenitors to hypoxia-ischemia. J Neurosci 22:455-463.

Beal MF, Kowall NW, Ellison DW, Mazurek MF, Swartz KJ, Martin JB (1986): Replication of the neurochemical characteristics of Huntington's disease by quinolinic acid. Nature 321 : 168-171.

-Bernert G, Gottling A, Rosenkranz A, Zoder G (1988): Hemorrhagic and hypoxic-ischemic intracranial lesions in neonates diagnosed by realtime sonography: Incidence and short-term outcome. Padiatr Padol 23:25-37.

- Blaumanis OR, Rennels ML, Grady PA (1990): Focal cerebral edema impedes convective fluid/tracer movement through paravascular pathways in cat brain. Adv Neurol 52:385389.

- Brightman MW, Reese TS (1969): Junctions between intimately apposed cell membranes in the vertebrate brain. J Cell Biol 40:648-677.

- Byravan S, Foster LM, Phan T, Verity AN, Campagnoni AT (1994): Murine oligodendroglial cells express nerve growth factor. Proc Natl Acad Sci USA 91:8812-8816.

Cooke RW (1999): Trends in incidence of cranial ultrasound lesions and cerebral palsy in very low birthweight infants 1982-93. Arch Dis Child Fetal Neonatal Ed 80:F115-F117.

- Counsell SJ, Allsop JM, Harrison MC, Larkman DJ, Kennea NL, Kapellou O, Cowan FM, Hajnal JV, Edwards AD, Rutherford MA (2003): Diffusion-weighted imaging of the brain in preterm infants with focal and diffuse white matter abnormality. Pediatrics 112:17.

Dai X, Lercher LD, Clinton PM, Du Y, Livingston DL, Vieira C, Yang L, Shen MM, Dreyfus CF (2003): The trophic role of oligodendrocytes in the basal forebrain. J Neurosci 23:58465853.

Dugan LL, Choi DW (1994): Excitotoxicity, free radicals, and cell membrane changes. Ann Neurol 35(suppl):S17-S21.

Geddes R, Vannucci RC, Vannucci SJ (2001): Delayed cerebral atrophy following moderate hypoxia-ischemia in the immature rat. Dev Neurosci 23:180-185.

-Graham EM, Sheldon RA, Flock DL, Ferriero DM, Martin LJ, O'Riordan DP, Northington FJ (2004): Neonatal mice lacking functional Fas death receptors are resistant to hypoxic-ischemic brain injury. Neurobiol Dis 17:89-98

- Graybiel AM, Aosaki T, Flaherty AW, Kimura M (1994): The basal ganglia and adaptive motor control. Science 265:1826-1831.

- Inder TE, Huppi PS, Warfield S, Kikinis R, Zientara GP, Barnes PD, Jolesz F, Volpe JJ (1999): Periventricular white matter injury in the premature infant is followed by reduced cerebral cortical gray matter volume at term. Ann Neurol 46:755-760.
Kawahara A, Ohsawa Y, Matsumura H, Uchiyama Y, Nagata S (1998): Caspase-independent cell killing by Fas-associated protein with death domain. J Cell Biol 143:1353-1360.

- Kettenmann H, Sonnhof U, Schachner M (1983): Exclusive potassium dependence of the membrane potential in cultured mouse oligodendrocytes. J Neurosci 3:500-505.

Lee WH, Wang GM, Seaman LB, Vannucci SJ (1996): Coordinate IGF-I and IGFBP5 gene expression in perinatal rat brain after hypoxiaischemia. J Cereb Blood Flow Metab 16:227236.

Levi G, Gallo V, Ciotti MT (1986): Bipotential precursors of putative fibrous astrocytes and oligodendrocytes in rat cerebellar cultures express distinct surface features and 'neuron-like' gamma-aminobutyric acid transport. Proc Natl Acad Sci USA 83:1504-1508.

Levison SW, Rothstein RP, Romanko MJ, Snyder MJ, Meyers RL, Vannucci SJ (2001): Hypoxia/ ischemia depletes the rat perinatal subventricular zone of oligodendrocyte progenitors and neural stem cells. Dev Neurosci 23:234-247.

Levison SW, Young GM, Goldman JE (1999): Cycling cells in the neocortex preferentially generate oligodendroglia. J Neurosci Res 57:435447.

- Maalouf EF, Duggan PJ, Rutherford MA, Counsell SJ, Fletcher AM, Battin M, Cowan F, Edwards AD (1999): Magnetic resonance imaging of the brain in a cohort of extremely preterm infants. J Pediatr 135:351-357.

-Martin LJ, Al-Abdulla NA, Brambrink AM, Kirsch JR, Sieber FE, Portera-Cailliau C (1998): Neurodegeneration in excitotoxicity, global cerebral ischemia, and target deprivation: A perspective on the contributions of apoptosis and necrosis. Brain Res Bull 46:281-309.

Matsumura H, Shimizu Y, Ohsawa Y, Kawahara A, Uchiyama Y, Nagata S (2000): Necrotic death pathway in Fas receptor signaling. J Cell Biol 151:1247-1256.

-McDonald JW, Levine JM, Qu Y (1998): Multiple classes of the oligodendrocyte lineage are highly vulnerable to excitotoxicity. Neuroreport 9: 2757-2762.

Mito T, Ando Y, Takeshita K, Takada K, Takashima S (1989): Ultrasonographical and morphological examination of subependymal cystic lesions of maturely born infants. Neuropediatrics 20:211-214.

Nagata S (1999): Fas ligand-induced apoptosis. Annu Rev Genet 33:29-55.

Ness JK, Scaduto RC, Wood TL (2004): IGF-I prevents glutamate-mediated Bax translocation and cytochrome $\mathrm{C}$ release in $\mathrm{O} 4$ oligodendrocyte progenitors. Glia 46:183-194.

Ness JK, Wood TL (2002): Insulin-like growth factor I, but not neurotrophin-3, sustains Akt activation and provides long-term protection of immature oligodendrocytes from glutamatemediated apoptosis. Mol Cell Neurosci 20: 476-488.
Nishiyama A, Lin XH, Giese N, Heldin CH, Stallcup WB (1996): Interaction between NG2 proteoglycan and PDGF alpha-receptor on O2A progenitor cells is required for optimal response to PDGF. J Neurosci Res 43:315-330.

Northington FJ, Ferriero DM, Flock DL, Martin LJ (2001a): Delayed neurodegeneration in neonatal rat thalamus after hypoxia-ischemia is apoptosis. J Neurosci 21:1931-1938.

- Northington FJ, Ferriero DM, Martin LJ (2001b): Neurodegeneration in the thalamus following neonatal hypoxia-ischemia is programmed cell death. Dev Neurosci 23:186-191.

- Ohata K, Marmarou A (1992): Clearance of brain edema and macromolecules through the cortical extracellular space. J Neurosurg 77:387396.

- Peterson BS, Vohr B, Staib LH, Cannistraci CJ, DolbergA, Schneider KC, KatzKH, Westerveld M, Sparrow S, Anderson AW, Duncan CC Makuch RW, Gore JC, Ment LR (2000): Regional brain volume abnormalities and longterm cognitive outcome in preterm infants. JAMA 284:1939-1947.

du Plessis AJ, Volpe JJ (2002): Perinatal brain injury in the preterm and term newborn. Curr Opin Neurol 15:151-157.

Preston RJ, Bishop GA, Kitai ST (1980): Medium spiny neuron projection from the rat striatum: an intracellular horseradish peroxidase study. Brain Res 183:253-263.

Pulsinelli WA (1985): Selective neuronal vulnerability: Morphological and molecular characteristics. Prog Brain Res 63:29-37.

- Reynolds R, Herschkowitz N (1984): Uptake of 3HGABA by oligodendrocytes in dissociated brain cell culture: A combined autoradiographic and immunocytochemical study. Brain Res 322:17-31

Rice JE, Vannucci RC, Brierley JB (1981): The influence of immaturity on hypoxic-ischemic brain damage in the rat. Ann Neurol 9:131141.

Romanko MJ, Rothstein RP, Levison SW (2004): Neural stem cells in the subventricular zone are resilient to hypoxia/ischemia whereas progenitors are vulnerable. J Cereb Blood Flow Metab $24: 814-825$.

Rothstein RP, Levison SW (2002): Damage to the choroid plexus, ependyma and subependyma as a consequence of perinatal hypoxia/ischemia. Dev Neurosci 24:426-436

Sapirstein VS, Strocchi P, Gilbert JM (1984): Properties and function of brain carbonic anhydrase. Ann NY Acad Sci 429:481-493.

Towfighi J, Mauger D, Vannucci RC, Vannucci SJ (1997): Influence of age on the cerebral lesions in an immature rat model of cerebral hypoxiaischemia: A light microscopic study. Brain Res Dev Brain Res 100:149-160.

Vannucci RC, Rossini A, Towfighi J, Vannucci SJ (1997): Measuring the accentuation of the brain damage that arises from perinatal cerebral hypoxia-ischemia. Biol Neonate 72:187-191.

- Vannucci SJ, Seaman LB, Vannucci RC (1996) Effects of hypoxia-ischemia on GLUT1 and GLUT3 glucose transporters in immature rat brain. J Cereb Blood Flow Metab 16:77-81. 